mastication being the eating of soft foods, we must also conclude that the latter practice is chiefly responsible for the disease in question; such foods further predispose to this affection in that they are apt to lodge between the teeth and by undergoing decomposition there to favour the growth of micro-organisms within the mouth. The condition of the teeth and gums among the civilised poor is, alas, little calculated to make us proud of our boasted civilisationthe spongy pus-exuding gums, the lengthening, loose, tartar-covered, carious teeth, and the putrescent breath constitute a damning indictment against our modern system of living on a soft, pappy diet and not giving the teeth the work for which they are designed. I never examine such a mouth without being impressed with, and I may add oppressed by, this fact.

I am not, of course, contending that pyorrhcea alveolaris only occurs in those who masticate inefficiently; whatever causes an unhealthy condition of the gums and saliva predisposes to it, but it is surely much less common in those whose masticate well than in those who masticate ill. Confirmatory of this statement is the fact that it is more frequent in those with irregular teeth than in those with a good bite, who are thus able to put their teeth to more effective use. This affection is very common among the carnivora of menageries as well as among dogs and cats; indeed, one seldom fails to find it in dogs over four years of age and in old dogs it is generally rampant. Doubtless in all these cases the general conditions of life play some part in the causation of the disease, but I do not think that we can eliminate from it the factor of defective use of the jaws and teeth, for it is certain that dogs and cats are fed largely on pappy foods and are often insufficiently supplied with bones.

The causation of dental caries.-Dr. Wallace, in his philosophical work on "The Cause and Prevention of Decay in Teeth," contends that the cause of the prevalence of dental caries is that the natural food-stuffs are to a large extent ridded of their accompanying fibrous parts and consumed in a form which renders them liable to lodge and to undergo acid fermentation in the mouth, while from the same cause and the induced conditions the micro-organisms of the mouth lodge and multiply and augment the rapidity and intensity of the acid fermentation. I am perfectly at one with Dr. Wallace in believing that the removal of the fibrous portions of food is the main cause of the prevalence of caries among moderns and I can hardly doubt that foods so prepared tend to promote caries in the way indicated, but I venture to think that they do this even more by failing to call forth the normal degree of mastication. I cannot but think that if these same soft foods were as laboriously masticated as they would need to be if they retained their fibrous ingredients, dental caries would be much less common than it actually is. I have endeavoured to show how very different the local conditions are in the efficient from what they are in the inefficient masticator-how in the former the jaws and teeth are wont to be well developed, the bite to be good, and the secretions which bathe the teeth to be of a kind calculated to promote their health, and how in the latter an entirely opposite set of conditions is wont to prevail. That it is possible to maintain a fine set of healthy teeth till past middle life on ordinary civilised diet, provided the food be habitually subjected to efficient mastication, is shown in the case of the man already referred to and by numerous other cases which I have observed.

Since the application of cooking to food there has been a progressive lessening in the work of the jaws and teeth and parallel with this a diminution in their size and an incursion of dental caries. Among the anthropoids in their natural state caries is practically unknown and $I$ think we may con. clude that the same was true of man before he learnt to cook. In the pre-agricultural races, such as the aboriginal Australians, the effect of cooking the food is shown in the lessening in the size of the wisdom teeth and of the post-wisdom alveolar ridge; dental caries though rare among these people does occur and especially in the wisdom teeth. ${ }^{7}$ In the early agricultural period, owing to

7 Among the Australian skulls I have examined in museums caries of the wisdom teeth-i.e.. in those very teeth which, as shown by their atrophy, are least used-is by no means uncommon (though it is possible that some of the skuls belong to natives who have embraced the dietetic customs of the white man) I submit that this fact may fairly teeth predisposes them to caries by interfering with their resisting teeth predisposes them to caries by interfering with their resisting wisdom teeth places them at a disadrantage owing to the tendency of food to accumulate about them, especially in undeveloped jaws in which they have to about them, esp the increasing softness of the vegetable food, the jaws and teeth show a tendency to be smaller than in the previous periods; the wisdom teeth are decidedly smaller and more prone to caries, while caries of the other teeth is by no means rare. In the late agricultural period the jaws and teeth often show very decided defects of development, while dental caries is, as we know but too well, rampant.

What has been said concerning the relative prevalence of caries in different diet epochs applies to many other diseases of the teeth; thus along with the increase of caries there has been a parallel increase in the prevalence of pyorrhœa alveolaris.

\section{Concluding REMARKS.}

I have now set forth some of the evils resulting from inefficient mastication. They are many and serious. The immediate evils, such as over-eating, indigestion, adenoids, dental caries, and pyorrhoea alveolaris, are bad enough, but when we consider the secondary evils to which these primary ones give rise, and I have only mentioned a few of them, we must come to the conciusion that an appalling amount of misery and suffering may be saved by the simple expedient of in. culcating the habit of efficient mastication. How this end can best be accomplished will be considered in the next section.

(To be concluded.)

\section{THE CONSERVATIVE TREATMENT OF LESIONS OF THE UTERINE} APPENDAGES. ${ }^{1}$

BY GEORGE GRANVILLE BANTOCK, M.D., F.R.C.S. EDIN.

THE conservative treatment of lesions of the uterine appendages has been the theme of discussion for several years. The question has been looked at from two different standpoints. The first is based on the desire to avoid the necessity for a second operation by removing the organ on the suspicion of disease in a very early stage. The second has in view the idea of treating the suspected organ so as to arrest the disease and to render retention possible. Both are acts of conservative surgery, although in appearance diametrically opposed to each another.

In the first instance it was maintained, as the result of experience, that if one ovary were diseased the other was very liable to be attacked. The argument was fortified by the frequency with which every extended list of ovariotomies showed a double operation in which the evidence of disease was unmistakeable. This was especially liable to occur in the case of the colloid tumour. My own list shows this in a marked degree, for is a very large majority of the cases of this kind the second ovary was already characteristically affected and in one instance I had to perform a second operation within three years. The same argument was used in the case of the Fallopian tube with even more weight and it was strongly held by the late $\mathrm{Mr}$. Lawson Tait that in the case of ectopic gestation it was the duty of the surgeon to remove both the tubes to prevent a similar occurrence in the other tube. He was able to support the argument and practice by several examples of this occurrence. When one Fallopian tube is the seat of the inflammatory process it is very rare that the other tube is free from the evidence of disease and therefore the operation is usually double. Nor is it difficalt to understand why this should be so. The Fallopian tubes are continuous with the uterus, not only by contiguity, but also by continuity of structure, both as regards their tissues, cavities, and vascular supply, and there is no evidence to show that inflammatory disease arises in the tubes without a corresponding condition in the uterus. No case of salpingitis or pyosalpinx has, to my knowledge, been recorded without the existence of the inflammatory process in the uterus at some time preceding the development of this condition According to the doctrine of to-day salpingitis is brought about by the passing of microbes from the uterus into the tube by continuity of way. It is scarcely necessary for me to say that $I$ do not accept this view, regarding it as a mere assumption based on the doctrine of the microbic origin of

1 A paper read (in Spanish) at the Fourteenth International Congress of Medicine held in Madrid in April, 1903. 
disease which I have elsewhere shown to be untenable. ${ }^{2}$ Be this as it may, clinical observation confirms the view I have stated above as to the implication of the two organs-the uterus and the tube-when the latter is found to be diseased. If, then, in operating on a case of ovarian cystoma we find the second ovary presenting distinct evidence of disease it is an act of true conservative surgery to remove that organ. In my opinion this practice is applicable, and with equal force, to the case of the Fallopian tube.

On the other hand, the second principle of treatment, as I have said, has in view the treatment of the suspected organ so as to arrest the disease and to render the retention of the organ possible. The principle is the same whether we employ the method of ignipuncture or excision of the suspected part. Now it is a difficult thing to say at the earliest stage whether an ovary is diseased or not. To this class especially has this treatment been directed and I am not at all satisfied that the basis is a sound one. It is all very well to point to a limited number of cases in which impregnation has followed this operation. This very fact appears to sustain my objection that these organs were not the seat of any disease at all. In many cases of ovariotomy I have been in considerable doubt as to the condition of the second ovary, but only once have I put this practice into force by evacuating a large Graafian follicle which was probably on the point of bursting. What the final result was I have never heard, but I certainly could not found any argument in favour of the proceeding on such a case. On the other hand, I have often been in considerable doubt, especially in the cases of young married women, and have abstained from interference with the happiest results. I recall one case in particular in which, after having removed a dermoid tumour of about three pounds in weight, the condition of the other ovary was such as to raise in my mind the gravest apprehension until, some months after, I heard that she was pregnant. This patient continues free from disease. It is a remarkable fact that in those cases in which I have had to operate a second time there was not the slightest suspicion of disease at the time of the first operation. The intervals varied from 18 years, 11 (in which case the woman bore twins-one of each sex-within 18 months) and three years, down to one year.

There is a third point of view from which this question may be considered-viz, the idea that the ovary is the source of an internal secretion which is of use in the economy and that on this account one ovary at least should be left behind in cases of complete hysterectomy. It is said that this practice renders the menopause more easy. I venture to repeat here what I have elsewhere said more than once, that there is not a particle of evidence to support this view of an internal secretion. It is merely an effort of the imagination. On the other hand, experience tells us that the menopause is not beneficially affected. I have recently placed on record a case of ovariotomy seven years after complete hysterectomy. ${ }^{3}$ In this case both ovaries, which appeared to be perfectly healthy, were left behind. Yet the symptoms of the menopause were unusually severe and protracted. This fact and the occurrence of disease so many years after furnish a strong argument against this practice. The idea has been handed down to us from the time when the pathology of the sexual organs was in a state of chaos that at the "change of life" the woman must necessarily suffer. Careful investigation, however, shows that the majority of women do not suffer any inconvenience and that whatever symptoms may be present they are due to the arrest of menstruation.

With regard to the condition of hydrosalpinx and to the operation of salpingostomy my own experience is not favourable. Nor does it appear that the general results of this operation give any support to the practice. When we consider that for the production of a hydrosalpinx it is necessary that both ends of the tube be occluded and that, while it may be quite possible to restore the infundibular end or to make a substitute for it, to render patulous the uterine end is not so easy of accomplishment. With this view the late Dr. Mundé proposed catheterisation of the uterine end, but his results do not appear to support the practice and it is not reasonable to suppose that a single catheterisation, even if it were practicable, could bring about

2 On the Importance of Gonorrbcea as a cause of Inflammation of the Pelvic Organs, Brit. Med. Jour., April 4th, 1891 ; and the Modern Doctrine of Bacteriology, \&c. a cure. Long experience has taught me that the ovary is usually regarded as the seat of disease (inflammation) when a patient complains of pain in the region of that organ. Hence we hear a great deal of acute and chronic ovaritis. I am convinced that the uterus is in these cases the true fons et origo mali and that the pain is reflex. This is confirmed by the fact that inspection of the uterus shows it to be congested and that when this is subdued the pain ceases. It is very rare that the pain of uterine congestion is referred to the uterus itself and when the sound is passed into the cavity or the cervix is struck by the finger in examination we have a sure means of determining the source of the pain. Moreover, in these cases the ovary is not more tender than usual.

A word of protest against that mania for operating-the caonethes operandi-which characterises the gynæcological surgery of the day. I have rescued from operation a considerable number of patients who had been condemned to suffer the loss of their uterine appendages on account of some supposed disease of the ovaries, one or both. All these patients are alive and well and some of them have borne children, one patient as many as four. I have also seen many cases in which the clinical evidence, pointing to severe inflammatory disease of the appendages, was overwhelming and in which the signs and symptoms all disappeared under appropriate treatment, and I cannot but believe that many cases are operated upon without sufficient justification.

I therefore draw the following conclusions : (1) that in the course of an ovariotomy it is true conservative surgery to remove the second ovary if it shows palpable disease; (2) that in the case of ectopic gestation or of salpingitis, either acute or chronic, it is advisable in the great majority of cases, if not in all, to do the double operation; (3) that the practice of ignipuncture or partial resection of a suspected ovary is not founded on specific data ; (4) that it is not true conservative surgery to leave an ovary in cases of complete hysterectomy ; and (5) that the operation of salpingostomy does not appear to me to have any claim to be regarded as worthy of acceptance.

\section{HAVE THE LOCALITY AND SURROUND- INGS AN INFLUENCE UPON THE RECURRENCE OF MALIGNANT DISEASE AFTER OPERA- TION ? ${ }^{1}$}

BY D'ARCY POWER, F.R.C.S. ENG.,

SENIOR SURGEON TO THE VICTORIA HOSPITAL FOR CHILDREN; CHELSEA ; ASSISTANT SURGEON TO ST. BARTHOLOMEW'S HOSPITAL, F.C.

You may reasonably inquire what business a surgeon has to address the members of a congress of public health? My answer will be in the words of the elephant's child in Rudyard Kipling's "Just-So" stories that it is "all along of my insatiable curiosity." I want to know the experience of my audience upon a matter about which I can get but little information from my own side of the profession. I want to know whether after an operation for malignant disease it is advisable or inadrisable to send a patient back to his old home and to his former surroundings, or whether it is better to recommend him to break altogether with his previous existence? In other words, have the locality and surroundings an influence upon the recurrence of malignant disease after a successful surgical operation? I will illustrate my meaning by some cases which bave lately come under my notice.

CASE 1.-A married woman, aged 50 years, whose mother had died from cancer and who had a well-marked tuberculous history, developed cancer of the breast. The mammary gland was removed and with it some enlarged glands from the axilla. I examined the breast and glands after removal and found them to be very malignant pathologically because there were many cells and little stroma. The prognosis, therefore, was bad as there seemed to be little doubt that recurrence would speedily take place and that the patient would die with secondary deposits. She belonged to a

1 A paper read at a meeting of the Royal Institute of Public Health held at Liverpool on July 16th, 1903. 